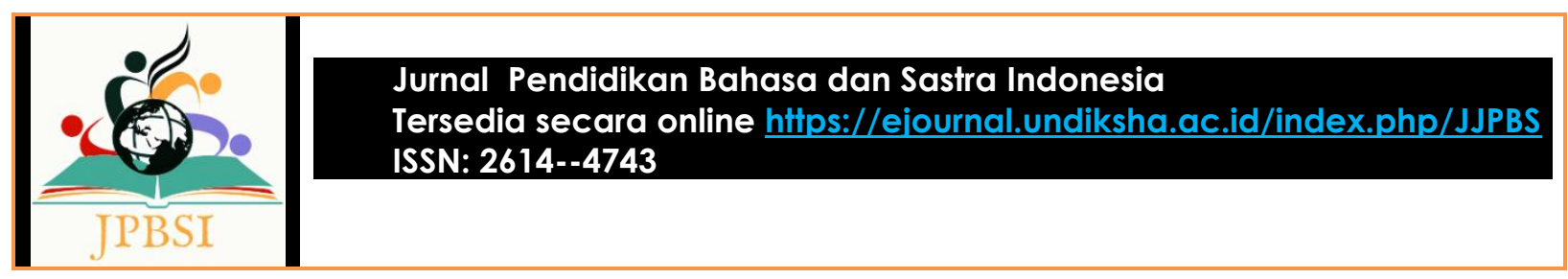

\title{
PENGGUNAAN APLIKASI QUIZLET DALAM KEGIATAN EVALUASI PEMBELAJARAN SURAT PRIBADI DAN SURAT DINAS PADA SISWA KELAS VII/I DI SMP NEGERI 10 DENPASAR
}

\author{
Ni Wayan Lindayani ${ }^{1}$, Gde Artawan ${ }^{2}$ \\ 1,2, Program Studi Pendidikan Bahasa Indonesia, Universitas Pendidikan Ganesha \\ Singaraja, Bali, Indonesia
}

Surel : niwayanlindayani480@gmail.com ${ }^{1}$, sastrawan.g@yahoo.com²,

\begin{tabular}{|c|c|}
\hline \multicolumn{2}{|r|}{ Abstrak } \\
\hline $\begin{array}{l}\text { Kata Kunci: Aplikasi } \\
\text { Quizlet; Evaluasi } \\
\text { Pembelajaran; Surat } \\
\text { Pribadi dan Surat } \\
\text { Dinas. }\end{array}$ & $\begin{array}{l}\text { Penelitian ini bertujuan mendeskripsikan penggunaan aplikasi Quizlet dalam kegiatan } \\
\text { evaluasi pembelajaran surat pribadi dan surat dinas pada siswa kelas VII/i di SMP } \\
\text { Negeri } 10 \text { Denpasar. Penelitian ini menggunakan rancangan deskriptif kualitatif. } \\
\text { Subjek dalam penelitian ini adalah siswa kelas VII/i SMP Negeri } 10 \text { Denpasar dan guru } \\
\text { Bahasa Indonesia yang mengajar di kelas VII/i SMP Negeri } 10 \text { Denpasar. Objek } \\
\text { penelitian ini adalah penggunaan aplikasi Quizlet dalam kegiatan evaluasi } \\
\text { pembelajaran surat pribadi dan surat dinas pada siswa kelas VII/i di SMP Negeri } 10 \\
\text { Denpasar. Data dikumpulkan dengan menggunakan metode observasi. Tahapan analisis } \\
\text { data meliputi reduksi data, penyajian data dan penarikan kesimpulan. Hasil penelitian } \\
\text { ini menunjukkan tentang penggunaan aplikasi Quizlet dalam kegiatan evaluasi } \\
\text { pembelajaran surat pribadi dan surat dinas. Sebelum guru melaksanakan kegiatan } \\
\text { evaluasi pembelajaran menggunakan aplikasi Quizlet, guru terlebih dahulu } \\
\text { melaksanakan tiga tahapan kegiatan pembelajaran, yakni kegiatan pendahuluan, } \\
\text { kegiatan inti, dan kegiatan penutup. Pada penggunaan aplikasi Quizlet dalam kegiatan } \\
\text { evaluasi pembelajaran surat pribadi dam surat dinas pada siswa kelas VII/i di SMP } \\
\text { Negeri } 10 \text { Denpasar, guru telah menyiapkan rangkaian kartu-kartu (flashcard) yang } \\
\text { pada aplikasi Quizlet yang berisi rangkuman bahan ajar surat pribadi dan surat dinas. } \\
\text { Guru telah mempersiapkan tes dengan menggunakan dua mode (mode learn dan mode } \\
\text { match) untuk siswa dalam melakukan kegiatan evaluasi pembelajaran terkait materi } \\
\text { surat pribadi dan surat dinas. Pada mode learn (pelajari), guru memberikan pertanyaan- } \\
\text { pertanyaan terkait dengan materi ajar yang sudah disediakan dalam flashcard. Pada } \\
\text { mode match terdapat } 6 \text { pasang kartu yang harus dicocokkan oleh siswa dan yang } \\
\text { mendapat nilai terbaik adalah siswa yang menjawab dengan tepat dan dengan waktu } \\
\text { tercepat. }\end{array}$ \\
\hline \multicolumn{2}{|r|}{ Abstract } \\
\hline $\begin{array}{l}\text { Keywords: Quizlet } \\
\text { application; Learning } \\
\text { Evaluatio; Personal } \\
\text { Letter and Official } \\
\text { Letter. }\end{array}$ & $\begin{array}{l}\text { This study aims to describe the use of the Quizlet application in the evaluation of } \\
\text { learning personal letters and official letters for class VII/i students at SMP Negeri } 10 \\
\text { Denpasar. This study used a qualitative descriptive design. The subjects in this study } \\
\text { were students of class VII/i of SMP Negeri } 10 \text { Denpasar and Indonesian teachers who } \\
\text { taught in class VII/i of SMP Negeri } 10 \text { Denpasar. The object of this research is the use } \\
\text { of the Quizlet application in the evaluation of learning personal letters and official } \\
\text { letters for class VII/i students at SMP Negeri } 10 \text { Denpasar. Data were collected using } \\
\text { the observation method. The stages of data analysis include data reduction, data } \\
\text { presentation and conclusion drawing. The results of this study indicate the use of the } \\
\text { Quizlet application in the evaluation of learning personal letters and official letters. } \\
\text { Before the teacher carries out learning evaluation activities using the Quizlet } \\
\text { application, the teacher first carries out three stages of learning activities, namely } \\
\text { preliminary activities, core activities, and closing activities. In using the Quizlet } \\
\text { application in the evaluation of learning personal letters and official letters for class } \\
\text { VII/i students at SMP Negeri } 10 \text { Denpasar, the teacher has prepared a series of cards } \\
\text { (flashcards) which in the Quizlet application contain a summary of teaching materials } \\
\text { forpersonal letters and official letters. The teacher has prepared a test using two modes }\end{array}$ \\
\hline
\end{tabular}




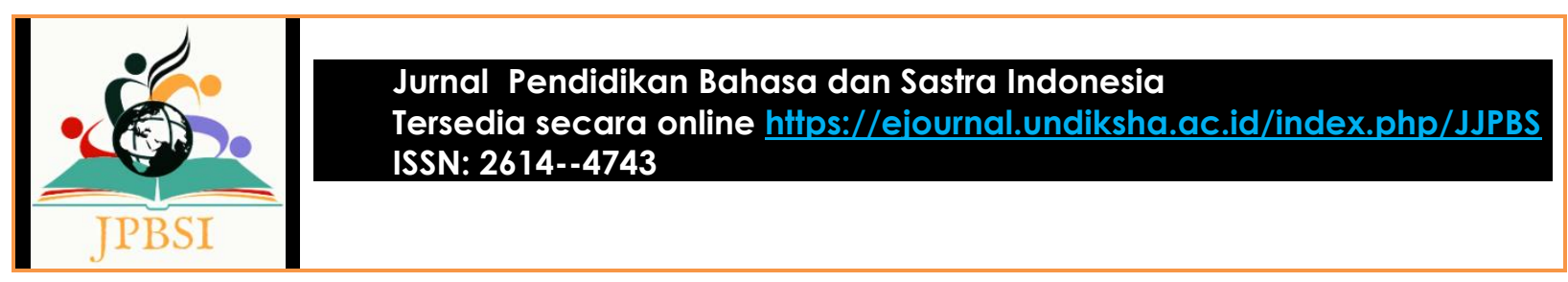

\begin{tabular}{|l|l|}
\hline & $\begin{array}{l}\text { (learn mode and match mode) for students to carry out learning evaluation activities } \\
\text { related to personal letter and official letter material. In learn mode, the teacher gives } \\
\text { questions related to the teaching materials that have been provided in the flashcard. In } \\
\text { match mode there are } 6 \text { pairs of cards that must be matched by students and the one } \\
\text { who gets the best score is the student who answers correctly and with the fastest time. }\end{array}$ \\
\hline $\begin{array}{l}\text { Diterima/direview/ } \\
\text { dipublikasi }\end{array}$ & 16 Agustus 2021/21 Agustus 2021/30 September 2021 \\
\hline
\end{tabular}

\section{PENDAHULUAN}

Pada awal tahun 2020, masyarakat di Indonesia digemparkan dengan adanya pandemi Covid19. Hingga saat ini pandemi Covid-19 masih melanda Indonesia. Pandemi ini sangat berdampak pada seluruh bidang yang ada, salah satunya dalam bidang pendidikan. Pendidikan formal yang biasanya dilakukan dengan tatap muka secara langsung di sekolah, kini harus terkendala dengan adanya pandemi Covid-19. Untuk mengatasi kendala tersebut, pemerintah memutuskan pembelajaran dilakukan secara daring (online).

Penerapan sistem pembelajaran daring yang dilakukan tanpa tatap muka secara langsung tentunya memiliki berbagai tantangan, salah satunya adalah fokus peserta didik yang berkurang karena tidak melakukan tatap muka secara langsung. Waktu pada saat pembelajaran daring pun menjadi sangat singkat sehingga keutuhan kegiatan pembelajaran yaitu kegiatan pembuka, isi, dan penutup serta kegiatan evaluasi menjadi terabaikan. Oleh karena itu, perlu adanya suatu media untuk menunjang pembelajaran daring yang dapat memotivasi peserta didik untuk tetap fokus dalam pembelajaran, membuat keutuhan kegiatan pembelajaran tetap terjamin dan kegiatan evaluasi dalam pembelajaran dapat terealisasi. Penggunaan media pembelajaran berbasis e-learning menjadi salah satu cara untuk pendidik agar tetap bisa melaksanakan kegiatan pembelajaran daring secara utuh terutama dalam kegiatan evaluasi pembelajaran.

Dalam kegiatan pembelajaran, evaluasi merupakan suatu kegiatan yang penting serta memberikan manfaat pencapaian hasil belajar siswa. Salah satu manfaat dari penilaian yaitu digunakan untuk mengukur sejauh mana kemampuan siswa maupun guru. Arikunto (2002) menyatakan evaluasi merupakan salah satu variabel yang menentukan keberhasilan belajar, sehingga guru dituntut untuk profesional dan kreatif. Evaluasi pada hakikatnya adalah suatu proses merencanakan, memperoleh, dan menyediakan informasi atau data yang diperlukan sebagai dasar untuk membuat alternatif keputusan. Bagi pendidik evaluasi berfungsi sangat penting dalam proses penilaian. Guru dapat mengetahui siswa mana yang bisa melanjutkan pelajaran karena sudah menguasai materi. Dengan begitu guru dapat memusatkan kepada siswa yang belum berhasil, guru juga dapat mengetahui apakah materi yang diajarkan sudah tepat bagi siswa sehingga guru akan mengoreksi akan pembelajaran. Bagi peserta didik evaluasi juga memiliki peran penting. Peserta didik dapat mengetahui sejauh mana telah berhasil mengikuti pelajaran yang diberikan oleh guru. Evaluasi merupakan suatu bagian yang tak terpisahkan dari pembelajaran itu sendiri. Oleh karena itu, evaluasi memiliki kedudukan yang sangat penting dalam kegiatan pembelajaran.

Salah satu jenis e-learning yang digunakan dalam kegiatan evaluasi pembelajaran adalah aplikasi Quizlet. Quizlet merupakan perangkat yang sederhana, mudah digunakan, dan inovatif yang dapat membantu jutaan siswa dalam pembelajaran daring. Quizlet dapat diakses melalui website. Pada hakikatnya, fungsi utama Quizlet memang digunakan untuk mengembangkan kecerdasan linguistik, terutama dalam hal memperkaya kosakata (Aribowo, 2015). Selain dapat memperkaya kosakata, aplikasi Quizlet juga dapat diimplementasikan sebagai media evaluasi diri dengan meminta siswa untuk menggunakan mode yang tersedia di aplikasi Quizlet. Hasil dari evaluasi tersebut, nantinya dapat digunakan untuk penilaian yang diambil oleh guru. Fitur-fitur pada aplikasi Quizlet telah diatur dengan baik dalam bentuk layanan kelas virtual, yang terdiri dari flashcard, learn, write, spell, test, match, 


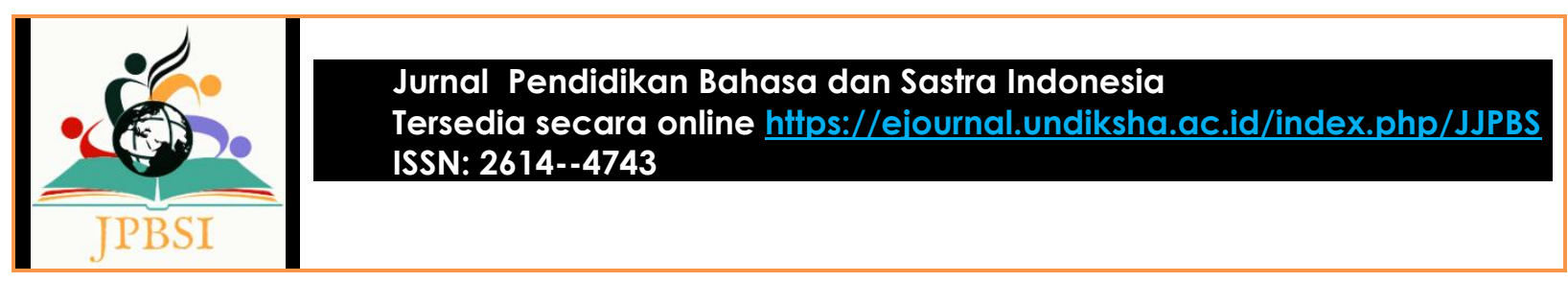

gravity, dan live. Beberapa cakupan dari fitur-fitur tersebut meliputi pengelolaan beberapa folder yang berisi kumpulan kartu flash dalam topik atau materi tertentu, memberikan batasan akses untuk anggota pengguna, dan mencatat skor pengguna saat menjalankan mode yang tersedia. Pada aplikasi Quizlet terdapat fitur flashcard yang dapat digunakan sebagai kartu tes saat melaksanakan evaluasi. Aplikasi Quizlet juga menyediakan fasilitas audiovisual yang bertujuan agar pengguna bisa mendengarkan pengucapan kata-kata yang ada dan memperhatikan gambar saat memainkan flashcard.

Penggunaan aplikasi Quizlet tentunya telah banyak diterapkan dalam dunia pendidikan. Salah satu sekolah yang menggunakan aplikasi Quizlet dalam evaluasi pembelajaran surat pribadi dan surat dinas adalah SMP Negeri 10 Denpasar yang menjadi salah satu sekolah favorit di Kota Denpasar. Menurut pengamatan yang telah dilakukan oleh peneliti, materi pembelajaran surat pribadi dan surat dinas muncul pada jenjang kelas VII dalam KD 4.14. Penelitian ini dilakukan oleh peneliti di kelas VII/i SMP Negeri 10 Denpasar. Peneliti memilih kelas tersebut karena kemampuan siswa di kelas VII/i lebih baik dibandingkan dengan kelas lain. Hal itu dibuktikan dari hasil observasi dan wawancara yang peneliti lakukan dengan guru mata pelajaran Bahasa Indonesia di SMP Negeri 10 Denpasar yaitu Bapak Krisna Sunarjaya, serta didukung dari nilai-nilai yang diperoleh oleh siswa-siswi kelas VII SMP Negeri 10 Denpasar yang diampunya. Hal ini juga dikarenakan langkah-langkah pembelajaran yang diterapkan dan media e-learning yang digunakan oleh guru pengampu sangat efektif sehingga mampu meningkatkan hasil belajar siswa dan mengurangi kecemasan siswa dalam proses pembelajaran daring.

Berdasarkan hal tersebut dan dilihat dari permasalahan yang ada, peneliti tertarik untuk meneliti tentang penggunaan aplikasi Quizlet dalam kegiatan evaluasi pembelajaran surat pribadi dan surat dinas pada siswa kelas VII/i di SMP Negeri 10 Denpasar. Penelitian ini penting dilakukan untuk mengetahui secara detail bagaimana penggunaan aplikasi Quizlet dalam kegiatan evaluasi pembelajaran surat pribadi dan surat dinas.

\section{METODE PENELITIAN}

Penelitian ini menggunakan rancangan penelitian deskriptif kualitatif. Menurut Gunawan (2014), penelitian dengan pendekatan kualitatif menekankan analisis proses dari proses berpikir secara induktif yang berkaitan dengan dinamika hubungan antara fenomena yang diamati, dan senantiasa menggunakan logika ilmiah. Menurut Darmadi (2014: 185), penelitian deskriptif kualitatif adalah penelitian yang berusaha menggambarkan sesuatu sebagaimana adanya dengan menggunakan katakata. Penelitian ini mendeskripsikan mengenai penggunaan aplikasi Quizlet dalam kegiatan evaluasi pembelajaran surat pribadi dan surat dinas pada siswa kelas VII/i di SMP Negeri 10 Denpasar.

Subjek dan objek merupakan sumber data yang penting dalam penelitian. Menurut Wendra (2019: 62) subjek penelitian adalah hal atau orang tempat variabel melekat dan yang dipermasalahkan dalam penelitian. Subjek dalam penelitian ini adalah siswa kelas VII/i SMP Negeri 10 Denpasar dan guru Bahasa Indonesia yang mengajar di kelas VII/i SMP Negeri 10 Denpasar. Mengenai objek penelitian, menurut Arikunto (2002: 117) objek penelitian merupakan hal yang dikaji dalam penelitian. Objek atau hal yang dikaji dalam penelitian ini adalah penggunaan aplikasi Quizlet dalam kegiatan evaluasi pembelajaran surat pribadi dan surat dinas. Metode pengumpulan data yang digunakan adalah metode observasi.

Dalam pengumpulan data, digunakan sejumlah instrumen penelitian. Instrumen penelitian merupakan alat yang digunakan untuk mendapatkan dan mengumpulkan data penelitian, sebagai langkah untuk menemukan hasil atau kesimpulan dari penelitian dengan tidak meninggalkan kriteria pembuatan instrumen yang baik (Arifin, 2014:3). Pemilihan instrumen penelitian bertujuan untuk mendukung penggunaan metode pengumpulan data. Instrumen ini digunakan untuk melengkapi data yang akurat dan relevan. Pada penelitian ini, instrumen yang digunakan adalah instrumen observasi berupa pedoman observasi. Peneliti mengamati tentang penggunaan aplikasi Quizlet yang dilakukan 


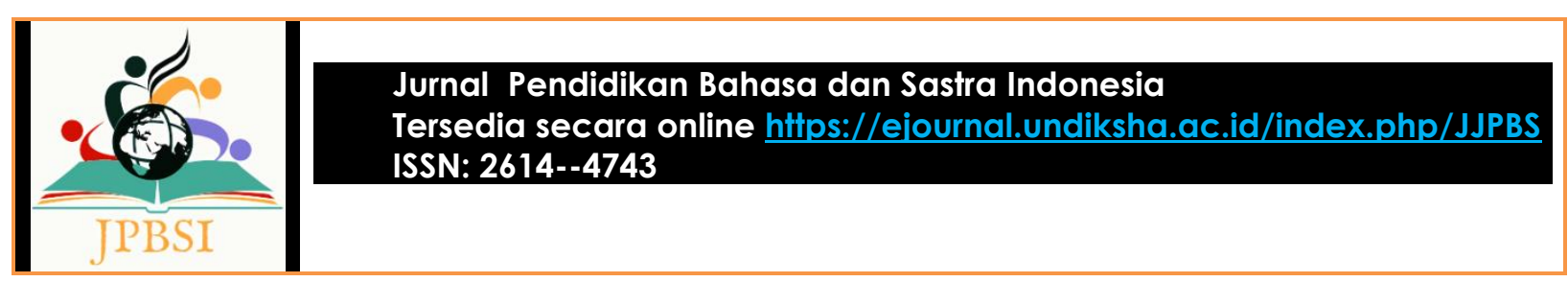

oleh guru dalam kegiatan evaluasi pembelajaran surat pribadi dan surat dinas sesuai dengan RPP, silabus, dan instrumen pembelajaran yang digunakan guru, lalu mencatat data yang telah didapatkan.

Teknik analisis data yang digunakan dalam penelitian ini adalah teknik analisis deskriptif kualitatif. Teknik analisis deskriptif kualitatif digunakan untuk mendeskripsikan dan menggambarkan kejadian data. Menurut Miles \& Huberman (1992:16), analisis terdiri dari tiga alur kegiatan yang terjadi secara bersamaan yaitu: reduksi data, penyajian data, penarikan kesimpulan/verifikasi. Analisis data dalam penelitian menggunakan model Miles \& Huberman yang ini terdiri dari reduksi data, penyajian data, dan penarikan simpulan. Data yang dianalisis adalah data yang diperoleh dari hasil observasi. Tahap pertama yang dilakukan, yaitu mereduksi data. Menurut Sugiyono (2017: 338), reduksi data berarti merangkum, memilih hal-hal pokok, memfokuskan hal-hal yang penting, dan membuang yang tidak perlu sehingga peneliti mendapatkan gambaran yang lebih jelas. Data mengenai penggunaan aplikasi Quizlet dalam kegiatan evaluasi pembelajaran surat pribadi dan surat dinas pada siswa kelas VII/i di SMP Negeri 10 Denpasar nantinya akan direduksi dengan cara memilih dan merangkum pokokpokok penting. Setelah mereduksi data, tahap selanjutnya yaitu, penyajian data. Pada tahap penyajian data, yang berhubungan dengan teori-teori yang relevan akan menjawab permasalahan yang ingin dipecahkan mengenai penggunaan aplikasi Quizlet dalam kegiatan evaluasi pembelajaran surat pribadi dan surat dinas pada siswa kelas VII/i di SMP Negeri 10 Denpasar. Langkah terakhir yang dilakukan, yaitu penarikan simpulan. Menurut Hardani, dkk. (2020:171) simpulan adalah inti sari dari temuan penelitian yang menggambarkan pendapat-pendapat terakhir yang berdasarkan pada uraian sebelumnya atau, keputusan yang diperoleh berdasarkan metode berpikir induktif atau deduktif. Pada penelitian ini, penarikan simpulan yang dilakukan harus dapat menjawab masalah yang diangkat dalam penelitian. Pada tahap ini diperoleh deskripsi mengenai penggunaan aplikasi Quizlet dalam kegiatan evaluasi pembelajaran surat pribadi dan surat dinas pada siswa kelas VII/i di SMP Negeri 10 Denpasar.

\section{HASIL DAN PEMBAHASAN}

Berdasarkan hasil observasi, diperoleh data mengenai penggunaan aplikasi Quizlet dalam kegiatan evaluasi pembelajaran surat pribadi dan surat dinas pada siswa kelas VII/i yang dilakukan oleh guru Bahasa Indonesia, Bapak Krisna Sunarjaya yang dilakukan pada Senin, 10 Mei 2021 pada pukul 08:00-10:00 WITA. Dari hasil observasi tersebut, Bapak Krisna Sunarjaya selaku guru Bahasa Indonesia di SMP Negeri 10 Denpasar memilih menggunakan aplikasi Quizlet sebagai media pembelajaran berbasis e-learning dalam kegiatan evaluasi pembelajaran surat pribadi dan surat dinas pada siswa kelas VII/i. Quizlet adalah perangkat yang sederhana, mudah digunakan, dan inovatif yang dapat membantu jutaan siswa untuk belajar melalui situs web dan aplikasi. Aplikasi Quizlet dapat diimplementasikan sebagai media evaluasi diri dengan meminta siswa untuk menggunakan mode yang tersedia pada aplikasi Quizlet.

Sebelum guru melaksanakan kegiatan evaluasi pembelajaran menggunakan aplikasi Quizlet, guru terlebih dahulu melaksanakan tiga kegiatan pembelajaran, yakni kegiatan pendahuluan, kegiatan inti, dan kegiatan penutup yang mana tiga kegiatan tersebut dilaksanakan melalui platform Google Classroom dan aplikasi Zoom.

Pada kegiatan pendahuluan, guru mempersiapkan pembelajaran dan menginformasikan kepada siswa melalui platform Google Classroom bahwa kegiatan pembelajaran surat pribadi dan surat dinas akan dimulai pukul 08:00 WITA melalui aplikasi Zoom. Guru lalu mengirim link Zoom 15 menit sebelum kegiatan pembelajaran dimulai. Pada pukul 08:00 WITA, guru dan siswa sudah bergabung pada aplikasi Zoom untuk memulai kegiatan pembelajaran. Sebelum kegiatan pembelajaran dimulai, guru terlebih dahulu membuka pembelajaran dengan mengucapkan salam dan berdoa bersama siswa/i. Setelah mengucapkan salam dan berdoa bersama, guru kemudian melakukan absensi dengan memanggil satu persatu siswa/i kelas VII/i pada aplikasi Zoom. Guru lalu melakukan apersepsi kepada siswa/i dengan cara menggali pengetahuan siswa mengenai surat pribadi dan surat dinas dan 


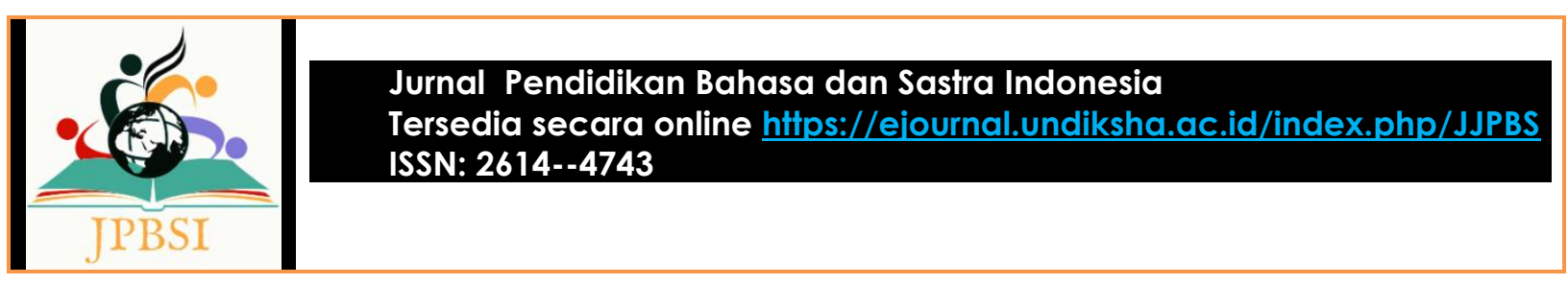

menyampaikan tujuan pembelajaran. Adapun tujuan pembelajaran yang disampaikan, yaitu siswa mampu menjelaskan pengertian surat pribadi dan surat dinas, dan siswa mampu mengidentifikasi ciriciri dan struktur surat pribadi dan surat dinas.

Pada kegiatan inti, guru menjelaskan materi surat pribadi dan surat dinas dalam bentuk PowerPoint. Siswa diminta untuk menyimak dan mencatat hal-hal penting yang disampaikan oleh guru. Guru menjelaskan pengertian surat pribadi, struktur surat pribadi, ciri-ciri surat pribadi, pengertian surat dinas, struktur surat dinas, dan ciri-ciri surat dinas. Setelah materi selesai dipaparkan, guru kemudian menampilkan contoh surat pribadi dan surat dinas. Guru waktu sekitar 10 menit untuk mengidentifikasi struktur dan ciri-ciri dari contoh surat yang ditampilkan pada PowerPoint. Guru melanjutkan dengan sesi diskusi bersama siswa untuk membahas hasil kerja sekaligus memperdalam pengetahuan siswa terkait materi surat pribadi dan surat dinas. Setelah sesi diskusi berakhir, guru bersama siswa menyimpulkan materi pelajaran yang telah dipelajari.

Setelah menyimpulkan materi pelajaran, guru lalu menutup kegiatan pembelajaran dengan mengucapkan salam dan menginformasikan kepada siswa untuk melakukan evaluasi pembelajaran terkait surat pribadi dan surat dinas pada aplikasi Quizlet dan meminta siswa untuk bergabung melalui link yang sudah guru berikan pada platform Google Classroom. Pada kegiatan evaluasi pembelajaran, guru telah menyiapkan rangkaian kartu-kartu yang pada aplikasi Quizlet disebut dengan flashcard. Berikut adalah contoh tampilan flashcard pada aplikasi Quizlet.

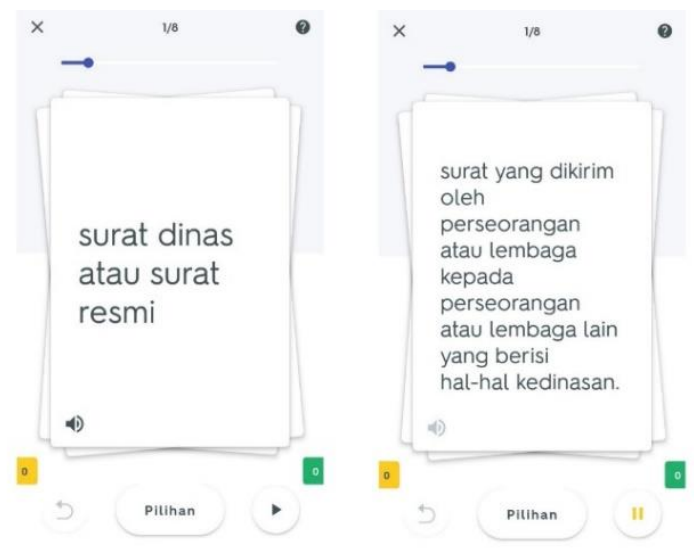

Gambar 1. Flashcard Aplikasi Quizlet

Flashcard tersebut berisi rangkuman bahan ajar yang disusun dalam bentuk kartu. Isi dari kartukartu tersebut antara lain, pengertian surat pribadi, ciri-ciri surat pribadi, struktur surat pribadi, pengertian surat dinas, ciri-ciri surat dinas, dan struktur surat dinas. Guru lalu membagikan link melalui platform Google Classroom dan meminta siswa untuk bergabung dalam kelas yang telah dibuat oleh guru pada aplikasi Quizlet. Melalui platform Google Classroom, guru memberikan informasi kepada siswa untuk memahami isi dari rangkaian kartu selama 10 menit. Guru telah mempersiapkan tes untuk siswa dalam melakukan kegiatan evaluasi pembelajaran terkait materi surat pribadi dan surat dinas yang telah dipaparkan sebelumnya pada aplikasi Zoom. Tes yang diberikan oleh guru menggunakan dua mode, yaitu mode learn dan mode match. Contoh tampilan mode learn (pelajari) dan mode match (mencocokkan) pada aplikasi Quizlet adalah sebagai berikut. 


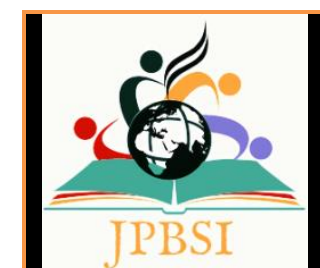

Jurnal Pendidikan Bahasa dan Sastra Indonesia

Tersedia secara online https://ejournal.undiksha.ac.id/index.php/JJPBS

\section{ISSN: 2614--4743}

C. Pelajar

ణ

$\times$

C. Pelajari

క్ㄱำ

gaya bahasa sangat personal, bebas, tidak resmi, serta boleh menggunakan bahasa sehari-hari; tidak sistematika penyusun surat baku; pesan, amanat,
dan isi surat beragam, tergantung mood dan isi surat beragam, tergantung mood pembuat; tidak memerlukan kop surat
dan aturan penulisan surat resmi lainnya

surat yang dikirim oleh perseorangan atau lembaga kepada perseorangan atau lembaga lain yang berisi hal-hal kedinasan.

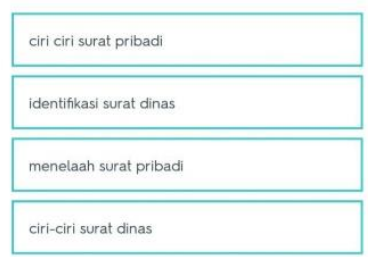

\begin{tabular}{|l|}
\hline surat dinas atau surat resmi \\
\hline surat pribadi \\
\hline identifikasi surat dinas \\
\hline identifikasi surat pribadi \\
\hline
\end{tabular}

Gambar 2. Mode Learn

\begin{tabular}{|c|c|c|}
\hline $\begin{array}{c}\text { surat dinas } \\
\text { hanya bersifat } \\
\text { menyampaikan } \\
\text { informasi. surat } \\
\text { dinas harus } \\
\text { memperhatik.. }\end{array}$ & $\begin{array}{c}\text { kepala surat; } \\
\text { nama tempat } \\
\text { dan tanggal; } \\
\text { nomor surat; } \\
\text { hal/perihal; } \\
\text { lampiran; } \\
\text { alama. }\end{array}$ & $\begin{array}{l}\text { identifikasi } \\
\text { surat dinas }\end{array}$ \\
\hline $\begin{array}{l}\text { gaya bahasa } \\
\text { sangat personal, } \\
\text { bebas, tidak } \\
\text { resmi, serta boleh } \\
\text { menggunakan } \\
\text { bahasa - }\end{array}$ & $\begin{array}{c}\text { identifikasi } \\
\text { surat } \\
\text { pribadi }\end{array}$ & $\begin{array}{c}\text { menelaah } \\
\text { surat } \\
\text { pribadi }\end{array}$ \\
\hline $\begin{array}{c}\text { surat } \\
\text { dinas } \\
\text { atau surat } \\
\text { resmi }\end{array}$ & $\begin{array}{l}\text { surat yang } \\
\text { dikirim oleh } \\
\text { perseorangan } \\
\text { atau lembaga } \\
\text { kepada } \\
\text { perseorangan } \\
\text { atau lemba.. }\end{array}$ & $\begin{array}{c}\text { Pembukaan } \\
\text { (ungkapan } \\
\text { syukur, } \\
\text { menyampaikan } \\
\text { kabar keluarga, } \\
\text { menanyakan } \\
\text { kegiatan yg ... }\end{array}$ \\
\hline $\begin{array}{c}\text { ciri ciri } \\
\text { surat } \\
\text { pribadi }\end{array}$ & $\begin{array}{c}\text { menelaah } \\
\text { surat } \\
\text { dinas }\end{array}$ & $\begin{array}{l}\text { tempat dan } \\
\text { tanggat } \\
\text { pembuatan surat; } \\
\text { tujuan/alamat } \\
\text { surat; salam } \\
\text { pemburka; } \\
\text { pembuka. }\end{array}$ \\
\hline
\end{tabular}

Gambar 3. Mode Match

Pada mode learn (pelajari), guru memberikan pertanyaan-pertanyaan terkait dengan materi ajar yang sudah disediakan dalam flashcard. Mode learn hampir sama dengan soal berbentuk Multiple Choice (MC), dimana peserta didik dapat memilih salah satu jawaban yang dirasa tepat. Benar atau salahnya pilihan jawaban akan langsung tertera pada layar seperti pada contoh gambar berikut. 

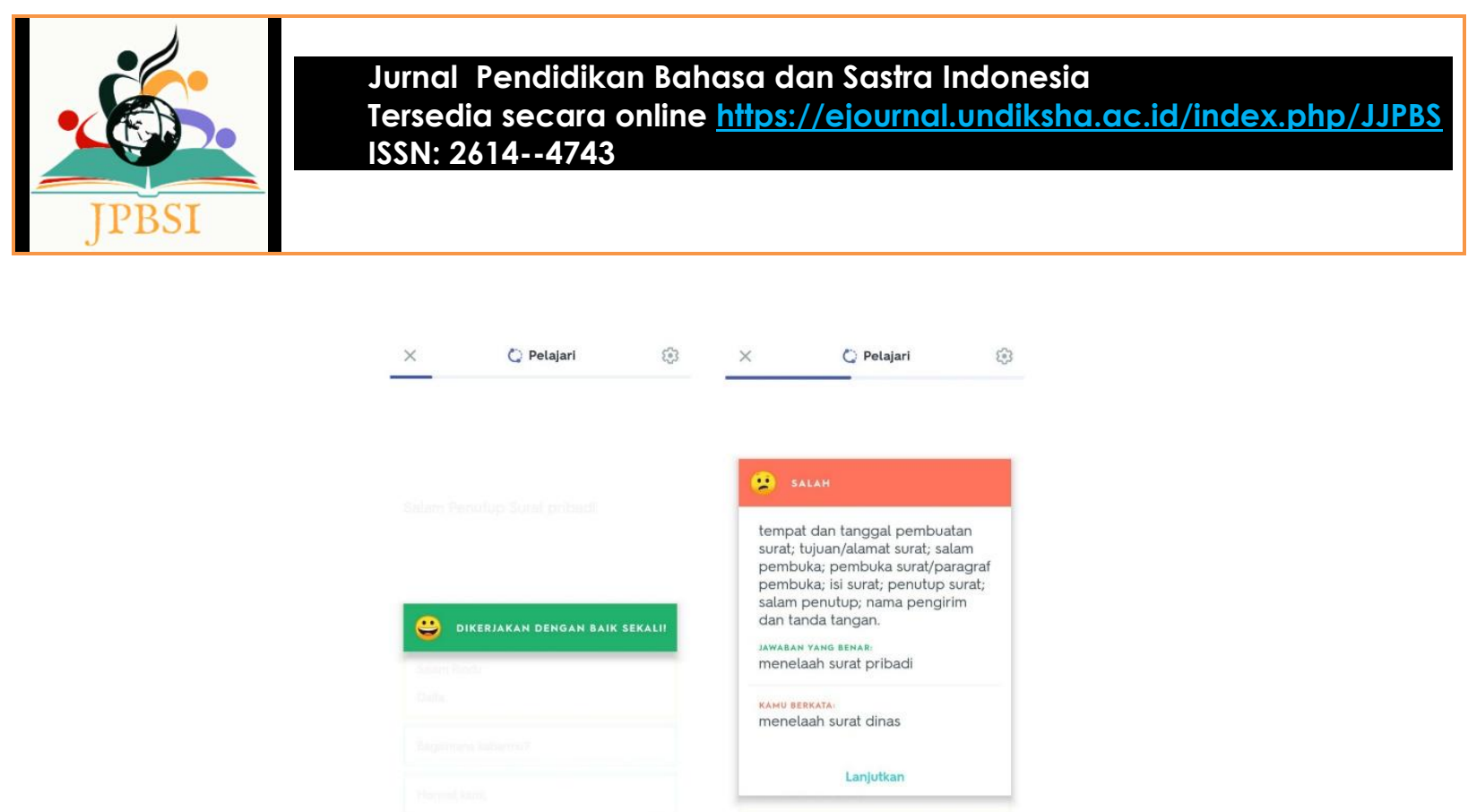

Gambar 4. Keterangan Benar atau Salah pada Mode Learn

Setelah 10 menit berlalu, guru kembali menginformasikan kepada siswa melalui platform Google Classroom terkait kegiatan evaluasi pembelajaran pada aplikasi Quizlet. Guru meminta siswa untuk membuka mode learn (pelajari) dan menjawab pertanyaan-pertanyaan yang telah disiapkan oleh guru pada mode tersebut. Waktu yang diberikan oleh guru kepada siswa adalah 5 menit. Untuk hasil jawaban akan langsung terlihat saat siswa selesai menjawab. Jika jawaban siswa salah, pemberitahuan yang berwarna merah akan ditampilkan. Namun jika jawaban siswa benar, pemberitahuan berwarna hijau yang akan ditampilkan. Selanjutnya, siswa diminta untuk membuka mode match (mencocokkan). Pada mode match terdapat 6 pasang kartu yang harus dicocokkan oleh siswa. Siswa yang mendapat nilai terbaik adalah siswa yang menjawab dengan tepat dan dengan waktu tercepat. Setelah siswa menjalankan dua mode ini, hasil kumulatif dari semua nilai siswa akan dicatat dalam grafik akun guru. Sistem akan secara otomatis mengurutkan hasil yang diperoleh siswa menurut urutan tiga teratas. Guru akan mengumumkan hasil tes agar siswa dapat memahami hasil proses pembelajaran.

Berdasarkan hasil observasi yang peneliti lakukan, sebelum guru melaksanakan kegiatan evaluasi pembelajaran menggunakan aplikasi Quizlet, guru terlebih dahulu melaksanakan tiga kegiatan pembelajaran, yakni kegiatan pendahuluan, kegiatan inti, dan kegiatan penutup. Tiga kegiatan inti tersebut dilaksanakan melalui platform Google Classroom dan aplikasi Zoom. Dilaksanakannya tiga kegiatan inti tersebut bertujuan agar keutuhan kegiatan pembelajaran tetap terlaksana dengan baik sebelum kegiatan evaluasi pembelajaran berlangsung. Setelah tiga kegiatan pembelajaran selesai dilaksanakan, guru kemudian melakukan kegiatan evaluasi pembelajaran. Kegiatan evaluasi pembelajaran ini bertujuan agar guru mengetahui kemajuan dan perkembangan serta keberhasilan siswa setelah melakukan kegiatan pembelajaran. Bapak Krisna Sunarjaya selaku guru Bahasa Indonesia di kelas VII/i SMP Negeri 10 Denpasar menggunakan aplikasi Quizlet dalam kegiatan evaluasi pembelajaran surat pribadi dan surat dinas. Pada aplikasi tersebut, guru memilih menggunakan mode learn dan mode match karena cocok untuk digunakan dalam kegiatan evaluasi pembelajaran surat pribadi dan surat dinas.

Pada mode learn, guru memberikan pertanyaan-pertanyaan terkait pembelajaran surat pribadi dan surat dinas yang telah dijelaskan oleh guru sebelumnya. Siswa nantinya akan memilih jawaban yang tepat sesuai dengan pertanyaan-pertanyaan yanv telah disiapkan oleh guru. Mode learn hampir sama dengan soal berbentuk Multiple Choice (MC), yang mana peserta didik dapat memilih salah satu jawaban yang dirasa tepat. Benar atau tidaknya pilihan jawaban akan langsung tertera pada layar. Pertanyaan-pertanyaan yang diberikan oleh guru kepada siswa pada mode learn meliputi, (1) surat yang dikirim oleh seseorang kepada orang lain yang isinya bersifat pribadi, (2) pembukaan (ungkapan 


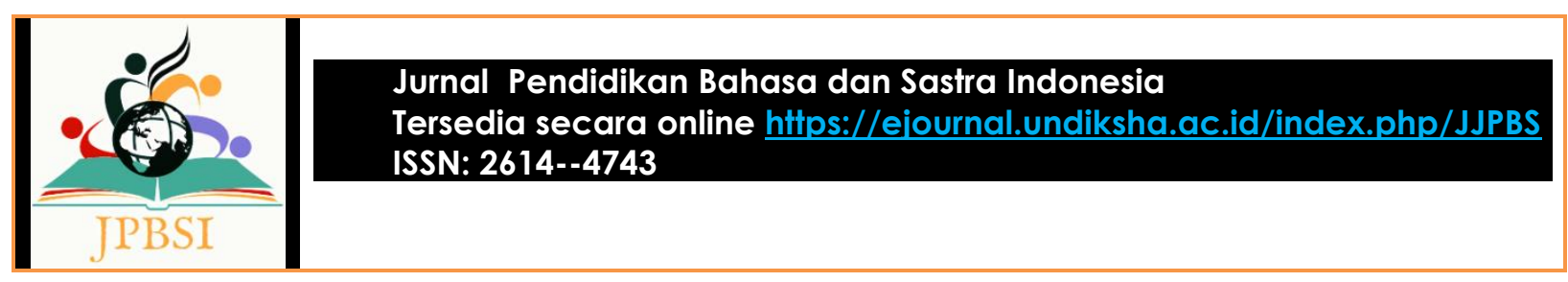

syukur, menyampaikan kabar keluarga, menanyakan kegiatan yg dilakukan); isi; penutup (ungkapan maaf, harapan), (3) kepala surat; nama tempat dan tanggal; nomor surat; hal/perihal; lampiran; alamat surat; salam pembuka; isi surat; salam penutup; tembusan, (4) gaya bahasa sangat personal, bebas, tidak resmi, serta boleh menggunakan bahasa sehari-hari; tidak sistematika penyusun surat baku; pesan, amanat, dan isi surat beragam, tergantung mood pembuat; tidak memerlukan kop surat dan aturan penulisan surat resmi lainnya, (5) surat yang dikirim oleh perseorangan atau lembaga kepada perseorangan atau lembaga lain yang berisi hal-hal kedinasan, (6) tempat dan tanggal pembuatan surat; tujuan/alamat surat; salam pembuka; pembuka surat/paragraf pembuka; isi surat; penutup surat; salam penutup; nama pengirim dan tanda tangan, dan (7) memiliki kepala atau kop surat yang merupakan nama dan alamat instansi tertentu; memiliki tanggal dan nomor surat; memiliki perihal, yaitu maksud dari surat tersebut dan lampiran; memiliki cap instansi tertentu pada bagian tanda tangan; menggunakan bahasa baku; memiliki tembusan.

Pada mode match (mencocokkan) yang merupakan salah satu fitur permainan pada aplikasi Quizlet. Mode ini dirancang untuk memasangkan kartu dengan pasangan yang benar. Pada mode ini juga disediakan pengatur waktu sehingga siswa dapat mengetahui waktu yang dibutuhkan untuk menyelesaikan setiap sesi (6 pasang kartu). Oleh karena itu, perolehan waktu yang dihasilkan dapat terekam. Nilai terbaik (waktu tercepat) akan dicatat dan digunakan sebagai kriteria untuk upaya selanjutnya. Pertanyaan-pertanyaan yang telah disiapkan oleh guru pada mode match yakni, (1) kalau sempat tolong balas suratku ini ya, (2) kami mohon izin untuk menggunakan ruangan tersebut, (3) Yth. Kepala SMP Negeri 10 Denpasar di Denpasar, (4) pilihan kata sapaan bersifat formal dan bahasa ragam baku, (5) surat resmi yang ditulis dalam situasi formal, dan (6) surat yang berisi keperluan pribadi yang biasanya ditulis seseorang kepada siapa pun yang berhubungan dengannya. Untuk pilihan jawaban dari pertanyaan-pertanyaan pada mode match tersebut juga telah disiapkan oleh guru yang meliputi, (1) surat dinas, (2) surat pribadi, (3) alamat surat dinas, (4) penutup surat pribadi, (5) permohonan izin pada surat dinas, dan (6) Ciri-ciri surat dinas.

Penerapan aplikasi pembelajaran yang digunakan oleh Bapak Krisna Sunarjaya selaku guru bahasa Indonesia di kelas VII/i SMP Negeri 10 Denpasar sudah menarik. Guru menggunakan aplikasi pembelajaran dengan tujuan agar kegiatan evaluasi dalam pembelajaran dapat terealisasi sekaligus memotivasi peserta didik untuk tetap fokus dalam pembelajaran dan memahami materi pelajaran dengan baik.

Melihat respons dan hasil kerja siswa dalam kegiatan evaluasi pembelajaran surat pribadi dan surat dinas dengan menggunakan aplikasi Quizlet yang rata-rata memperoleh nilai di atas KKM (Kriteria Ketuntasan Minimum), lebih membuktikan bahwa strategi yang dilakukan oleh guru dalam kegiatan evaluasi pembelajaran dengan menggunakan aplikasi Quizlet sudah sangat tepat. Respon dan hasil yang diberikan oleh siswa dengan menggunakan aplikasi Quizlet dalam kegiatan evaluasi pembelajaran surat pribadi dan surat dinas tersebut, mampu memberikan pemahaman yang baik serta membuat siswa mampu mengerjakan soal-soal pada aplikasi Quizlet dan mencapai keberhasilan dalam proses pembelajaran. Jika semua pembelajaran didukung dengan memanfaatkan penggunaan aplikasi pembelajaran yang tepat dan strategi yang tepat pula, keberhasilan siswa dalam pembelajaran bahasa Indonesia akan mencapai peningkatan. Hal tersebut sesuai dengan hasil pengamatan yang dilakukan peneliti.

\section{PENUTUP}

Ada tiga tahapan pembelajaran yang dilakukan oleh guru sebelum menggunakan aplikasi Quizlet dalam kegiatan evaluasi pembelajaran, yakni kegiatan pendahuluan, kegiatan inti, dan kegiatan penutup. Pada kegiatan pendahuluan, guru mempersiapkan pembelajaran dan menginformasikan kepada siswa melalui platform Google Classroom bahwa kegiatan pembelajaran surat pribadi dan surat dinas melalui aplikasi Zoom. Pada kegiatan inti, guru menjelaskan materi surat pribadi dan surat dinas 


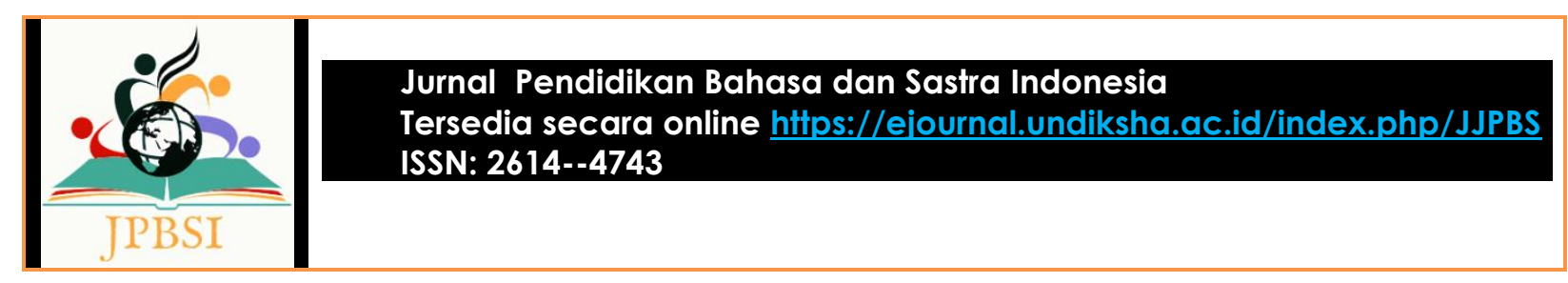

dalam bentuk PowerPoint dan siswa diminta untuk menyimak dan mencatat hal-hal penting yang disampaikan oleh guru. Pada kegiatan penutup, guru mengucapkan salam dan menginformasikan kepada siswa untuk melakukan evaluasi pembelajaran terkait surat pribadi dan surat dinas pada aplikasi Quizlet dan meminta siswa untuk bergabung melalui link yang sudah guru berikan pada platform Google Classroom. Pada kegiatan evaluasi pembelajaran, guru telah menyiapkan rangkaian kartu-kartu (flashcard) yang pada aplikasi Quizlet yang berisi rangkuman bahan ajar surat pribadi dan surat dinas. Guru telah mempersiapkan tes dengan menggunakan dua mode (mode learn dan mode match) untuk siswa dalam melakukan kegiatan evaluasi pembelajaran terkait materi surat pribadi dan surat dinas. penelitian ini masih terbatas karena hanya meneliti penggunaan aplikasi Quizlet dalam kegiatan evaluasi pembelajaran surat pribadi dan surat dinas saja. Untuk menambah khazanah keilmuan khususnya di bidang bahasa Indonesia, peneliti lain juga dapat meneliti penggunaan aplikasi dalam kegiatan evaluasi pembelajaran materi lainnya. Dalam proses pembelajaran, aplikasi Quizlet juga sangat bagus digunakan dalam materi lainnya, seperti dalam materi pembelajaran teks prosedur, cerita fantasi dan lain-lain.

\section{DAFTAR PUSTAKA}

Aribowo, Eric Kunto. 2015. Quizlet: Penggunaan Aplikasi Smartphone untuk Siswa dalam Mendukung Mobile Learning. https://www.academia.edu/download/56728048/Eric_Kunto_Aribowo.pdf.

Arifin, Muhamad dan Khoirudin Asfani. 2014. Instrumen Penelitian Kualitatif, Kuantitatif, dan Pengembangan. Universitas Negeri Malang. https://www.academia.edu/35055944/INSTRUMEN_PENELITIAN_KUALITATIF_KUAN TITATIF DAN PENGEMBANGAN pdf.

Arikunto, S. 2002. Metodelogi Penelitian. Jakarta: PT Rineka Cipta.

Darmadi, Hamid. 2014. Metode Penelitian Pendidikan dan Sosial/Teori Konsep Dasar dan Implementasi. Bandung: Alfabeta

Gunawan, Imam. 2014. Metode Penelitian Kualitatif. http://repo.iaintulungagung.ac.id/5670/6/BAB\%20III.pdf.

Hardani, dkk. 2020. Metode Penelitian Kualitatif \& Kuantitatif. Yogyakarta: Pustaka Ilmu.

Milles dan Huberman. 1992. Analisis Data Kualitatif. Jakarta: Universitas Indonesia Press.

Sugiyono. 2017. Metode Penelitian Pendidikan Pendekatan Kuantitatif, Kualitatif, dan R\&D. Bandung: Penerbit Albeta.

Wendra, I Wayan. 2019. Penulisan Karya Ilmiah (Penulisan Proposal Penelitian, Skripsi, dan Artikel). Singaraja: Universitas Pendidikan Ganesha

Copyright holder: @ Lindayani, N. W. \& Artawan. G. (2021)

Fist publication right: Jurnal Pendidikan Bahasa dan Sastra Indonesia Undiksha

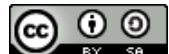

